\title{
Syndemic Theory and Male Same Sex Intimate Partner Violence: An Urban/Non-Urban Comparison
}

\author{
Matt L. Pimentel, An-Lin Cheng, Patricia J. Kelly \\ School of Nursing and Health Studies, University of Missouri-Kansas City, Kansas City, USA \\ Email: matt pim2004@yahoo.com
}

Received 4 March 2015; accepted 20 March 2015; published 24 March 2015

Copyright (C) 2015 by authors and OALib.

This work is licensed under the Creative Commons Attribution International License (CC BY). http://creativecommons.org/licenses/by/4.0/

(c) (i) Open Access

\begin{abstract}
Background: The majority of research with gay men has been conducted in urban populations, with minimal work on partner violence in non-urban (suburban and rural) settings. Syndemic theory, the concept that negative health outcomes are increased with the addition of each new deleterious health variable, has been used to understand partner violence. The aim of the study was to determine differences in prevalence and associated factors of male same-sex intimate partner violence (MSSIPV) among gay men residing in urban versus non-urban settings. Methods: A cross-sectional survey was conducted with gay men in the state of California. Variables were identified from syndemic theory and included exposure to intimate partner violence, depression, sexual compulsivity, poly-drug use, and childhood sexual abuse. Results: Demographic differences were evident between urban and non-urban dwelling gay men. Rates of lifetime victimization and perpetration of MSSIPV between urban and non-urban gay men were not significant. In regard to syndemic variables, only childhood sexual abuse (CSA) showed any significant differences between the two populations. Being a victim of CSA increased the odds of being a lifetime victim of MSSIPV by a factor of five for non-urban participants and increased the odds of being a victim by a factor of three for all subjects. Moreover, being a victim of CSA increased the odds of being a lifetime perpetrator of MSSIPV by a factor of three for non-urban participants. Conclusion: This appears to be the first of its kind study differentiating between urban and non-urban MSM. More research is needed to verify our findings of demographic and syndemic differences between these two populations in order to fully understand and address the needs of all members of the Lesbian, Gay, Bisexual, and Transgender (LGBT) community.
\end{abstract}

\section{Keywords}

Same Sex Intimate Violence, Non-Urban Populations, Urban Populations, Gay Men

Subject Areas: Nursing

How to cite this paper: Pimentel, M.L., Cheng, A.-L. and Kelly, P.J. (2015) Syndemic Theory and Male Same Sex Intimate Partner Violence: An Urban/Non-Urban Comparison. Open Access Library Journal, 2: e1407.

http://dx.doi.org/10.4236/oalib.1101407 


\section{Background}

Intimate partner violence affects couples in all population groups, including men who have sex with men (MSM), (a category including gay and bisexual men as well as men who do not so identify, but do intermittently have sex with men) [1]. Male same-sex intimate partner violence (MSSIPV) has been defined as "a pattern of violent and cohesive behaviors where by a gay man seeks to control the thoughts, beliefs, or conduct of an intimate partner or to punish the intimate [partner] for resisting the perpetrator's control” ([2], p. 17). Among gay men, prevalence rates of emotional, physical, and/or sexual MSSIPV vary between $14 \%-62 \%$ [3]. In the United States, between $1.8 \%$ and $4.9 \%$ of the male population self-identify as either gay or bisexual, suggesting that 956,000 men are exposed to MSSIPV [4]. Over the past twenty years, a variety of studies have examined the prevalence of MSSIPV and found greatly varying results, a result of differencing definitions of self-identity, lack of random samples, and lack of standardized instruments [5].

\subsection{Syndemic Theory}

A syndemic is a combination of interrelated variables that explain negative health outcomes for certain populations of individuals or subgroups [6]. The term was further enhanced by researchers while describing gay men or MSM, where certain variables would in combination, be more deleterious for gay men's healthcare outcomes than just compared to one variable alone [7]. Singer and colleagues originally developed the idea of a syndemic in his examination of the co-occurrence of substance abuse, violence, and HIV/AIDS, among Puerto Rican men in Hartford, Connecticut [8]. These factors which worked synergistically, as an example, substance abuse and HIV/AIDS in this population mutually reinforced each other and made the rate of each more extreme than if they had occurred alone [6]. Factoring in violence increased each variable even more. Other syndemics have been suggested for the confluence of risk behaviors found in certain Hispanic populations and for the problems facing women in the criminal justice system [9] [10]. Acknowledging the existence of a syndemic allows researchers and clinicians to focus on the interactions of these factors and to provide comprehensive interventions.

\subsection{Non-Urban Dwelling Gay Men}

While large numbers of young gay men approach urban areas for acceptance, social support, and vital services, many also remain in non-urban (suburban and rural) areas, in which there is limited information or services for MSSIPV abuse [11]. Living in non-urban areas can leave gay men in physical isolation, without the vital social support of a large LGBT community [12]. Many of these areas are socially conservative, with the majority of the residents supporting anti-gay views and strict limitations on LGBT rights [13].

In many non-urban communities, gay men generally are not "out" and, out of necessity, develop a number of coping mechanisms to hide their sexual orientation, including marriage to a female, homosexual behavior on the "down low," and "hooking up" with men in urban areas, local parks, bookstores, and vis-à-vis the internet [14]. Unfortunately, meeting sexual partners online and covert sexual activity are associated with higher rates of unprotected anal intercourse and drug use [15]. Partners procured from internet web sites tend to be sexually compulsive and willing to participate in high-risk sexual activity [16]. The gay men who take part in covert sexual activities are more internally homophobic and less “out," both factors associated with MSSIPV [17].

Few studies have focused on the non-urban (suburban and rural) prevalence of MSSIPV. Limiting our understanding of MSSIPV in non-urban populations is the unfortunate function that studies done in rural areas tend to have small sample sizes, often with less than 50 participants, because recruitment of gay men is a challenge in these areas [11]. Technologies are now available to enlarge sample size through internet and digital sampling [18]. An initial step in addressing this gap is this current descriptive survey to document the prevalence of MSSIPV, demographic information, and correlates in a population of non-urban (suburban and rural) gay men. The goal of this current study was to use syndemic theory to understand the factors associated with MSSIPV in a sample of non-urban gay men and comparing them to urban dwelling gay men. The aim of the study was to compare rates and correlates of MSSIPV among gay men living in urban and non-urban communities.

\section{Methods}

A cross-sectional survey was conducted to determine rates of MSSIPV and its correlates in several non-urban and urban counties of California. The study area included respondents from the following counties: San Luis 
Obispo, Santa Barbara, Monterey, Fresno, Kern, Kings, Tulare, Madera, Ventura, Los Angeles, San Diego, San Francisco, and Marin. Cities with populations over 100,000 were considered urban, populations from 50,000 100,000 were considered suburban, and city populations under 50,000 were considered rural. Permission to conduct the study was obtained from the Institutional Review Board of the University of Missouri-Kansas City.

\subsection{Sampling}

The sample for this cross-sectional survey was gathered through a face-to-face survey conducted at a regional Gay Pride Festival held in a rural/suburban area of California, supplemented by online surveys from social media sites. Because of the limited number of acknowledged gay men/MSM at any venue who would be available for study participation, the use of diverse sampling strategies (such as this one) is acceptable for studying this population [19]. Inclusion criteria were men who were 1) over the age of 18, 2) in a current or past MSM cohabitating relationship with another man, 3) able to read and understand English, and 4) residing in the counties of interest. Exclusion criteria included stated difficulty in answering questions about their personal life.

The sample included 406 gay, bisexual, or men who have sex with men (MSM) living in the State of California. Using the recommendation of Polit and Beck [20] of 20 subjects per variable, with four variables plus an additional 50 subjects, this sample size was adequate to answer the research questions. Since the minimum of 130 subjects were required for adequate power. Since 406 is larger than 130, the power was adequate.

\subsection{Measures}

Instruments to assess variables of syndemic theory for the specific problem of MSSIPV were used for this study. Demographic data included income, age, education level, race, ethnicity, HIV-infection status.

Depression was measured with the twenty-item CES-D or Centers for Epidemiological Studies Depression scale. The CES-D has been widely used and has questions such as, "I thought my life had been a failure," and, "my sleep was restless." This instrument has an alpha of 0.87, indicating strong reliability [21]. A total score of 16 or greater indicated significant symptoms of depression [22].

Childhood sexual abuse (CSA) was measured with one question: "Did anyone take advantage of you sexually who was at least 5 years older than you when you were 16 and under?” [23].

Poly-drug use was measured and defined with one question: "Have you used 3 or more recreational drugs in the past 90 days (meth, cocaine, marijuana, crack, Ecstasy, Ketamine, poppers, LSD, or someone else's pharmaceuticals, etc.)" [23].

Sexual compulsivity was assessed with the ten-item Sexual Compulsivity Scale, which has been tested on many gay men and has an alpha of 0.90 [24]. The scale uses a four-point Likert scale for responses and includes items such as, "my sexual appetite has gotten in the way of my relationships." Scores of 24 or greater indicate compulsivity [23].

Physical assault as either a victim or a perpetrator of IPV, the primary outcome variables for MSSPIV, was measured with the eighteen-item, eight-point Likert scale, for physical assault and injury components of the revised Conflicts Tactics Scale-2 [25] [26]. Lifetime rates were utilized. This subscale has an alpha of 0.86 [27].

\subsection{Data Analysis}

IBM SPSS (Version 22.0) software was used for data analysis. Descriptive statistics were used to summarize demographics and frequencies of all variables. Student $t$-tests and Chi-square $\left(X^{2}\right)$ tests were used to compare differences in syndemic-related variables between urban and non-urban populations. Logistic regression was conducted on the entire sample to assess whether the four syndemic predictor variables of depression, CSA, poly-drug use, and sexual compulsivity, predicted being either a victim or a perpetrator of MSSIPV. Separate logistic regression models were also conducted for urban and non-urban population.

\subsection{Procedures}

Potential participants were approached at the "Gay Pride in the Plaza" event in San Luis Obispo, CA, held in July 2013. Interested participants provided contact information and an email was sent after the event to confirm interest and provide a link to the internet survey through the data collection software program, Survey Monkey (SM). 


\section{Results}

The sample consisted of 406 gay, bisexual and MSM who ranged from 18 to 79 years of age (mean = 38.28, SD = 14.67; 138 (34\%) lived in an urban area and 268 (66\%) in a non-urban (suburban or rural) area. Compared to the local population, the sample was ethnically diverse, with 260/64.0\% identifying as non-Hispanic White, 78/19.2\% as Hispanic, and 68/16.7\% as African-American, multiracial, or other. Income levels had a normal distribution, with 111/27.3\% earning less than \$24,999, 108/26.6\% earning between \$25,000 - \$49,999, 80/19.7\% earning $\$ 50,000$ - $\$ 79,999$, and $81 / 19.9 \%$ earning $\$ 80,000$ or more. Only 39/9.6\% had a high school diploma or less, $120 / 29.6 \%$ had some college, $152 / 37.4 \%$ had graduated from college, and 69/17.0\% had a post graduate degree. The majority of the sample was HIV-negative 331/81.5\%; however, 34/8.4\% was HIV-positive, and $15 / 3.7 \%$ reported “don’t know.” Urban and non-urban participants were significantly different in income ( $p=$ $0.026)$ and education $(p=0.003)$ levels. These results are presented in Table 1.

\section{Table 1. Demographics of sample.}

\begin{tabular}{|c|c|c|c|c|}
\hline & Total N = 406 & Urban $N=138 / 34 \%$ & Rural/suburban N = 268/66\% & $p$ \\
\hline \multicolumn{5}{|l|}{ Age } \\
\hline 21 and under & $46 / 11.3 \%$ & $9 / 6.5 \%$ & $37 / 13.8 \%$ & \multirow{5}{*}{0.086} \\
\hline $22-30$ & $110 / 27.1 \%$ & $41 / 29.7 \%$ & $69 / 25.7 \%$ & \\
\hline $31-40$ & $73 / 18.0 \%$ & $27 / 20.0 \%$ & $46 / 17.2 \%$ & \\
\hline $41-50$ & $77 / 19.0 \%$ & $32 / 23.2 \%$ & $45 / 16.8 \%$ & \\
\hline 51 and over & $100 / 24.6 \%$ & $29 / 21.0 \%$ & $71 / 26.5 \%$ & \\
\hline \multicolumn{5}{|l|}{ Race } \\
\hline Non-Hispanic White & $260 / 64.0 \%$ & $87 / 63.0 \%$ & $173 / 64.6$ & \multirow{4}{*}{0.938} \\
\hline Hispanic & $78 / 19.2 \%$ & $28 / 20.3 \%$ & $50 / 18.7$ & \\
\hline African-American & $11 / 2.7 \%$ & $3 / 2.2 \%$ & $8 / 3.0 \%$ & \\
\hline Multiracial/other & $57 / 14.0 \%$ & $20 / 14.5 \%$ & $37 / 13.8 \%$ & \\
\hline \multicolumn{5}{|l|}{ Income } \\
\hline 0 - \$24,999 & $111 / 27.3 \%$ & $29 / 21.0 \%$ & $82 / 30.6 \%$ & \multirow{4}{*}{0.026} \\
\hline$\$ 25,000-\$ 49,999$ & $108 / 26.6 \%$ & $41 / 29.7 \%$ & $67 / 25.0 \%$ & \\
\hline$\$ 50,000$ - \$79,999 & $80 / 19.7 \%$ & $39 / 28.3 \%$ & $41 / 15.3 \%$ & \\
\hline$\$ 80,000$ and up & $81 / 20.0 \%$ & $29 / 21.0 \%$ & $52 / 19.4 \%$ & \\
\hline \multicolumn{5}{|l|}{ Education } \\
\hline High school or less & $39 / 9.6 \%$ & $7 / 5.1 \%$ & $32 / 11.9 \%$ & \multirow{4}{*}{0.003} \\
\hline Some college & $120 / 30.0 \%$ & $35 / 25.4 \%$ & $85 / 31.7 \%$ & \\
\hline College graduate & $152 / 37.4 \%$ & $63 / 45.7 \%$ & $89 / 33.2 \%$ & \\
\hline Postgraduate & $69 / 17.0 \%$ & $33 / 23.9 \%$ & $36 / 13.4 \%$ & \\
\hline \multicolumn{5}{|l|}{ HIV status } \\
\hline Positive & $34 / 8.4 \%$ & $13 / 9.4 \%$ & $21 / 7.8 \%$ & \multirow{3}{*}{0.167} \\
\hline Negative & $331 / 81.5 \%$ & $123 / 89.1 \%$ & $208 / 77.6 \%$ & \\
\hline Don’t know & $15 / 3.7 \%$ & $2 / 1.4 \%$ & $13 / 4.9 \%$ & \\
\hline
\end{tabular}




\section{Rates}

The rate of lifetime physical MSSIPV among participants was 139/34.2\%, while lifetime physical perpetration was 123/30.3\%. Table 2 shows these results.

The bivariate analysis (see Table 3) found that only CSA was significant when comparing participants living in urban and non-urban areas $(p=0.040)$. The other syndemic variables of depression, poly-drug use, sexual compulsivity, and MSSIPV for victim and perpetrator were not significant when comparing those who reside in urban areas versus non-urban areas.

When considered together, the four predictor variables (see Table 4) were statistically significant in predicting being a victim of lifetime physical MSSIPV $\left(X^{2}=13.126, d f=4, \mathrm{~N}=305, p=0.011\right)$. When considered together, no predictor variables (See Table 5) were significant in predicting whether a person was a perpetrator of lifetime physical MSSIPV $\left(X^{2}=6.198, d f=4, N=305, p=0.185\right)$.

Table 6 presents the odds ratios, which suggest that the odds of victimization increased 3.034 times when being a victim of CSA (OR = 3.034, 95\% CI 1.463, 6.294) for all participants. These odds were greater for nonurban participants who had a 5.22 times greater chance of reporting victimization of MSSIPV when having a history of CSA (OR = 5.22, 95\% CI 2.194, 12.42).

There was a slight significance between higher self-reports of depression and lifetime victimization, though not significant enough when the population was split between urban and non-urban participants. There were no significant associations between MSSIPV victimization and poly-drug use nor sexual compulsivity.

Table 2. Lifetime physical/injury \& victim/perpetrator of MSSIPV.

\begin{tabular}{cc} 
MSSIPV & N/\% \\
\hline Lifetime physical/injury victim of MSSIPV & $139 / 34.2 \%$ \\
Lifetime physical/injury perpetrator of MSSIPV & $123 / 30.3 \%$ \\
\hline
\end{tabular}

Table 3. Bivariate scores on syndemic-related variables.

\begin{tabular}{|c|c|c|c|c|}
\hline Scale & Total $\mathrm{N}=406$ & Urban $\mathrm{N}=138 / 34 \%$ & Rural/suburban N = 268/66\% & $p$ \\
\hline Depression & $\mathrm{N}=305$ & $\mathrm{~N}=105$ & $\mathrm{~N}=200$ & \\
\hline$\geq 16$ & 101/33.1 & $38 / 36.2 \%$ & $63 / 31.5 \%$ & 0.408 \\
\hline Under 16 & $204 / 66.9$ & $67 / 63.8 \%$ & $137 / 68.5 \%$ & \\
\hline Childhood sexual abuse & $\mathrm{N}=314$ & $\mathrm{~N}=107$ & $N=207$ & \\
\hline Yes & $44 / 14.0$ & $9 / 8.4 \%$ & $35 / 16.9 \%$ & 0.040 \\
\hline No & $270 / 86.0$ & 98/91.6 & $172 / 83.1 \%$ & \\
\hline Poly-drug use & $\mathrm{N}=314$ & $\mathrm{~N}=107$ & $\mathrm{~N}=207$ & \\
\hline Yes & $52 / 16.6$ & $18 / 16.8 \%$ & $34 / 16.4 \%$ & 0.928 \\
\hline No & $262 / 83.4$ & $89 / 83.2 \%$ & $173 / 83.6 \%$ & \\
\hline Sexually compulsivity & $\mathrm{N}=406$ & $\mathrm{~N}=138$ & $N=268$ & \\
\hline Score of $\geq 24$ (yes) & 137/33.7 & $48 / 34.8 \%$ & $89 / 33.2 \%$ & 0.751 \\
\hline Score $<24$ (no) & $269 / 66.3$ & $90 / 65.2 \%$ & $179 / 66.8 \%$ & \\
\hline MSSIPV-victim & $N=406$ & $\mathrm{~N}=138$ & $N=268$ & \\
\hline Yes & $139 / 34.2$ & $47 / 34.1 \%$ & $92 / 34.3 \%$ & 0.957 \\
\hline No & $267 / 65.8$ & $91 / 65.9 \%$ & $176 / 65.7 \%$ & \\
\hline MSSIPV-perpetrator & $\mathrm{N}=406$ & $\mathrm{~N}=138$ & $\mathrm{~N}=268$ & \\
\hline Yes & $123 / 30.3$ & $39 / 28.3 \%$ & $84 / 31.3 \%$ & 0.522 \\
\hline No & $283 / 69.7$ & $99 / 71.7 \%$ & $184 / 68.7 \%$ & \\
\hline
\end{tabular}


The logistic regression results were not significant for perpetrator of all subjects of MSSIPV. However, nonurban participants (see Table 7) had a 3.343 times greater chance of being a perpetrator of MSSIPV, $(\mathrm{OR}=$ 3.343, 95\% CI 1.339, 8.344).

\section{Discussion}

The rates of MSSIPV and syndemic variables range widely in research studies. Our survey with a convenience sample of MSM that were recruited at a gay pride event found an overall rate of lifetime victimization of MSSIPV at $34.2 \%$ and a lifetime perpetration rate of $30.2 \%$, both of which fall into the range found in prior studies and meta-reviews [28]. Comparing rates of MSSIPV is challenging because many studies use different instruments, different definitions and time periods (e.g., one-year vs. lifetime), and enmesh physical, emotional, and sexual abuse, into one value of MSSIPV. In this study, we focused on lifetime rates of physical and injury of MSSIPV victimization and perpetration, and further differentiated between urban (victim $=34.1 \%$; perpetrator $=$ $28.3 \%$ ) and non-urban (victim $=34.3 \%$; perpetrator $=31.3 \%$ ) rates. The combination of these specific syndemic variables were collectively significant for lifetime MSSIPV victimization but not for lifetime MSSIPV perpetration for all participants. However, that was not the focus of this study. We were looking at some of the individual

Table 4. Results of victimization of MSSIPV.

\begin{tabular}{ccccc}
\hline Type & Chi-square & df (degrees of freedom) & N & $p$ \\
\hline MSSIPV victimization & 13.126 & 4 & 305 & $\mathbf{0 . 0 1 1}$ \\
\hline
\end{tabular}

Table 5. Results of perpetration of MSSIPV.

\begin{tabular}{|c|c|c|c|c|}
\hline Type & chi-square & $d f$ (degrees of freedom) & $\mathbf{N}$ & $p$ \\
\hline MSSIPV perpetration & 6.198 & 4 & 305 & 0.185 \\
\hline
\end{tabular}

Table 6. Results of logistic regression for victimization.

\begin{tabular}{cccc}
\hline Variable & $\begin{array}{c}\text { Total sample } \\
\text { odds ratio/confidence intervals } \\
\mathbf{N}=\mathbf{3 0 5}\end{array}$ & $\begin{array}{c}\text { Urban participants } \\
\text { odds ratio/confidence intervals } \\
\mathbf{N}=\mathbf{1 0 5}\end{array}$ & $\begin{array}{c}\text { Non-urban participants } \\
\text { odds ratio/confidence intervals } \\
\mathbf{N}=\mathbf{2 0 0}\end{array}$ \\
\hline Depression & $1.026[1.001,1.052]^{*}$ & $1.014[0.976,1.053]$ & $1.033[0.999,1.069]$ \\
CSA & $3.034[1.463,6.294]^{*}$ & $0.435[0.048,3.963]$ & $5.22[2.194,12.42]^{* *}$ \\
Poly-drug & $0.748[0.320,1.752]$ & $1.822[0.539,6.159]$ & $0.394[0.107,1.453]$ \\
Sexual compulsivity & $0.913[0.549,1.517]$ & $1.062[0.509,2.213]$ & $0.787[0.384,1.612]$ \\
Constant & 0.142 & 0.163 & 0.134
\end{tabular}

${ }^{*} p<0.05, \stackrel{* *}{p} p<0.001$

Table 7. Results of logistic regression analysis for perpetrator.

\begin{tabular}{cccc}
\hline Variable & $\begin{array}{c}\text { Total sample } \\
\text { odds ratio/confidence intervals } \\
\mathbf{N}=\mathbf{3 0 5}\end{array}$ & $\begin{array}{c}\text { Urban participants } \\
\text { odds ratio/confidence intervals } \\
\mathbf{N}=\mathbf{1 0 5}\end{array}$ & $\begin{array}{c}\text { Non-urban participants } \\
\text { odds ratio/confidence intervals } \\
\mathbf{N}=\mathbf{2 0 0}\end{array}$ \\
\hline Depression & $0.997[0.968,1.028]$ & $0.999[0.976,1.053]$ & $0.993[0.955,1.032]$ \\
CSA & $2.217[0.977,5.031]$ & 0.000 & $3.343[1.339,8.344]^{* *}$ \\
Poly-drug & $0.591[0.215,1.656]$ & $0.958[0.539,6.159]$ & $0.533[0.146,1.951]$ \\
Sexual compulsivity & $1.406[0.815,2.425]$ & $1.639[0.509,2.213]$ & $1.322[0.641,2.727]$ \\
Constant & 0.079 & 0.060 & 0.088 \\
\hline
\end{tabular}

${ }^{*} p<0.05,{ }^{* *} p<0.001$. 
variables of syndemic theory. The lack of significant differences in rates of victimization and perpetration between these two populations may provide a first step in identifying and discussing other differences between those that live in urban vs. rural/suburban areas. These results can be construed as encouraging so resources and interventions can be similar from urban to non-urban, allowing researchers to focus efforts on effective interventions rather than dissimilarities.

Overall rates of CSA were $14 \%$, though significantly $(p=0.040)$ different between urban $(8.4 \%)$ and nonurban (16.9\%) populations. The total rate of CSA was lower in our study than in previous studies [29] [30]. But, like MSSIPV rates of abuse, response rates are contingent on the type of questions asked. Our study used a single question to determine rates of CSA while other studies used multiple questions for determination [30] [31].

We found that amongst the syndemic variables, only CSA correlated highly with lifetime victimization of MSSIPV. This correlation is consistent with other studies of lifetime and 12-month history of MSSIPV and CSA [32]-[35]. Logistic regression analysis showed that non-urban gay men had significant differences from urban gay men for both victim and perpetrator rates. Since we are not familiar of any other study that differentiates these two populations, it is difficult to accurately interpret these results. One possible reason could be the difference of social support for young gay men in rural areas compared to urban areas, where many gay men in the former being "guarded" about their sexual orientation identity [11]. CSA may be discussed less in non-urban settings due to the conservative nature of the communities and stigma of sexual minority status in rural areas [36] [37].

There are several limitations to our study. As this was a cross-sectional, preliminary research study, so we cannot infer causal relationships between the variables. Convenience sample studies make results difficult to be generalized to the entire gay/MSM community. In addition, recruitment occurred data gay pride event, which suggests that potential participants had some level of acceptance of their sexuality. MSM who are recruited at such venues may be different from those in the larger MSM community, with one study finding higher rates of sexual risk behaviors and numbers of sexual partners among those who frequent such events [29]. All variables were self-reported, which introduces the possibility of differential recall or recall bias [38].

\section{Conclusion}

Despite these limitations, this study appears to the first to measure many syndemic variables between urban and non-urban dwelling MSM. This information can be useful in developing targeted outreach with these two populations, and providing a launching step for future research.

\section{References}

[1] De Santis, J.P., et al. (2008) The Relationship of Depressive Symptoms, Self-Esteem, and Sexual Behaviors in a Predominantly Hispanic Sample of Men Who Have Sex with Men. American Journal of Men's Health, 2, 314-321. http://dx.doi.org/10.1177/1557988307312883

[2] Hart, B. (1986) Lesbian Battering: A Examination. In: Lobel, K., Ed., Naming the Violence, Seal Press, Seattle.

[3] Randle, A.A. and Graham, C.A. (2012) A Review of the Evidence on the Effects of Intimate Partner Violence on Men. http://www.apa.org/pubs/journals/releases/men-12-2-97.pdf

[4] Stephenson, R., Khosropour, C. and Sullivan, P. (2010) Reporting of Intimate Partner Violence among Men Who Have Sex with Men in an Online Survey. Western Journal of Emergency Medicine, 11, 242-246.

[5] Chen, P.H., Jacobs, A. and Rovi, S.L. (2013) Intimate Partner Violence: IPV in the LGBT Community. FP Essentials, 412, 28-35.

[6] Singer, M. (1996) A Dose of Drugs, a Touch of Violence, a Case of AIDS: Conceptualizing the SAVA Syndemic. Free Inquiry in Creative Sociology, 24, 99-110.

[7] Stall, R., Friedman, M. and Catania, J.A. (2008) Interacting Epidemics and Gay Men’s Health: A Theory of Syndemic Production among Urban Gay Men. In: Wolitski, R.J., Stall, R. and Valdiserri, R.O., Eds., Unequal Opportunity: Health Disparities Affecting Gay and Bisexual Men in the United States, Oxford University Press, New York, 251-274.

[8] Singer, M. (1994) AIDS and the Health Crisis of the U.S. Urban Poor: The Perspective of Critical Medical Anthropology. Social Science Medicine, 39, 931-948. http://dx.doi.org/10.1016/0277-9536(94)90205-4

[9] González-Guarda, R.M., Florom-Smith, A.L. and Thomas, T. (2011) A Syndemic Model of Substance Abuse, Intimate Partner Violence, HIV Infection, and Mental Health among Hispanics. Public Health Nursing, 28, 366-378. http://dx.doi.org/10.1111/j.1525-1446.2010.00928.x 
[10] Kelly, P.J., et al. (2014) A Syndemic Model of Women Incarcerated in Community Jails. Public Health Nursing, 31, 118-125. http://dx.doi.org/10.1111/phn.12056

[11] Lee, M.G. and Quam, J.K. (2013) Comparing Supports for LGBT Aging in Rural versus Urban Areas. Journal of Gerontological Social Work, 56, 112-126. http://dx.doi.org/10.1080/01634372.2012.747580

[12] Ristock, J.L. (2005) Relationship Violence in Lesbian/Gay/Bisexual/Transgender/Queer [LGBTQ] Communities: Moving beyond a Gender-Based Framework. Violence against Women Online Resources, University of Minnesota, Minnesota.

[13] Bowen, A.M., Horvath, K. and Williams, M.L. (2007) A Randomized Control Trial of Internet-Delivered HIV Prevention Targeting Rural MSM. Health Education Research, 22, 120-127. http://dx.doi.org/10.1093/her/cyl057

[14] Kennedy, M.G. (2010) Rural Men, Sexual Identity and Community. Journal of Homosexuality, 57, 1051-1091. http://dx.doi.org/10.1080/00918369.2010.507421

[15] Horvath, K.J., Bowen, A.M. and Williams, M.L. (2006) Virtual and Physical Venues as Contexts for HIV Risk among Rural Men Who Have Sex with Men. Health Psychology, 25, 237-242. http://dx.doi.org/10.1037/0278-6133.25.2.237

[16] Kakietek, J., Sullivan, P.S. and Heffelfinger, J.D. (2011) You’ve Got Male: Internet Use, Rural Residence, and Risky Sex in Men Who Have Sex with Men Recruited in 12 U.S. Cities. AIDS Education and Prevention, 23, 118-127. http://dx.doi.org/10.1521/aeap.2011.23.2.118

[17] Schnarrs, P.W., Rosenberger, J.G., Satinsky, S., Brinegar, E., Stowers, J., Dodge, B. and Reece, M. (2010) Sexual Compulsivity, the Internet, and Sexual Behaviors among Men in a Rural Area of the United States. AIDS Patient Care and STDs, 24, 563-569. http://dx.doi.org/10.1089/apc.2010.0117

[18] Bowen, A.M., Williams, M.L., Daniel, C.M. and Clayton, S. (2008) Internet Based HIV Prevention Research Targeting Rural MSM: Feasibility, Acceptability, and Preliminary Efficacy. Journal of Behavioral Medicine, 31, 463-477. http://dx.doi.org/10.1007/s10865-008-9171-6

[19] Medicine, I.O. (2011) The Health of Lesbian, Gay, Bisexual, and Transgender People: Building a Foundation for a Better Understanding. The National Academies Press, Washington DC, 347.

[20] Polit, D.F. and Beck, C.T. (2012) Nursing Research: Generating and Assessing Evidence for Nursing Practice. Vol. 9, J. B. Lippincott, Williams \& Wilkins, New York.

[21] Radloff, L.S. (1977) The CES-D Scale: A Self-Report Depression Scale for Research in the General Population. Applied Psychological Measurement, 1, 385-401. http://dx.doi.org/10.1177/014662167700100306

[22] Dyer, T.P., Shoptaw, S., Guadamuz, T.E., Plankey, M., Kao, U., Ostrow, D., et al. (2012) Application of Syndemic Theory to Black Men Who Have Sex with Men in the Multicenter AIDS Cohort Study. Journal of Urban Health, 89, 697-708. http://dx.doi.org/10.1007/s11524-012-9674-x

[23] Parsons, J.T., Grov, C. and Golub, S.A. (2012) Sexual Compulsivity, Co-Occurring Psychosocial Health Problems, and HIV Risk among Gay and Bisexual Men: Further Evidence of a Syndemic. American Journal of Public Health, 102, 156-162. http://dx.doi.org/10.2105/AJPH.2011.300284

[24] Kalichman, S.C. and Rompa, D. (2001) The Sexual Compulsivity Scale: Further Development and Use with HIV Positive Persons. Journal of Personality Assessment, 76, 379-395. http://dx.doi.org/10.1207/S15327752JPA7603_02

[25] Straus, M.A., Hamby, S.L., Boney-McCoy, S. and Sugarman, D.B. (1996) The Revised Conflict Tactics Scales (CTS2): Development and Preliminary Psychometric Data. Journal of Family Issues, 17, 283-316. http://dx.doi.org/10.1177/019251396017003001

[26] Nowinski, S.N. and Bowen, E. (2012) Partner Violence against Heterosexual and Gay Men: Prevalence and Correlates. Aggression and Violent Behavior, 17, 36-52. http://dx.doi.org/10.1016/j.avb.2011.09.005

[27] Straus, M.A. and Douglas, E.M. (2004) A Short Form of the Revised Conflict Tactics Scales, and Typologies for Severity and Mutuality. Violence and Victims, 19, 507-520. http://dx.doi.org/10.1891/vivi.19.5.507.63686

[28] Finneran, C. and Stephenson, R. (2013) Intimate Partner Violence among Men Who Have Sex with Men: A Systematic Review. Trauma, Violence, \& Abuse, 14, 168-185. http://dx.doi.org/10.1177/1524838012470034

[29] Phillips, G., Magnus, M., Kuo, I., Rawls, A., Peterson, J., Montanez, L., et al. (2014) Childhood Sexual Abuse and HIV-Related Risks among Men Who Have Sex with Men in Washington, DC. Archives of Sexual Behavior, 43, 771778. http://dx.doi.org/10.1007/s10508-014-0267-5

[30] Han, S.C., Gallagher, M.W., Franz, M.R., Chen, M.S., Cabral, F.M. and Marx, B.P. (2013) Childhood Sexual Abuse, Alcohol Use, and PTSD Symptoms as Predictors of Adult Sexual Assault among Lesbians and Gay Men. Journal of Interpersonal Violence, 28, 2505-2520. http://dx.doi.org/10.1177/0886260513479030

[31] Balsam, K.F., Rothblum, E.D. and Beauchaine, T.P. (2005) Victimization over the Life Span: A Comparison of Lesbian, Gay, Bisexual, and Heterosexual Siblings. Journal of Consulting and Clinical Psychology, 73, 477-487. http://dx.doi.org/10.1037/0022-006X.73.3.477

[32] De Santis, J.P., Gonzalez-Guarda, R., Provencio-Vasquez, E. and Deleon, D.A. (2013) The Tangled Branches (Las 
Ramas Enredadas): Sexual Risk, Substance Abuse, and Intimate Partner Violence among Hispanic Men Who Have Sex with Men. Journal of Transcultural Nursing, 25, 23-32. http://dx.doi.org/10.1177/1043659613504110

[33] Andersen, J.P. and Blosnich, J. (2013) Disparities in Adverse Childhood Experiences among Sexual Minority and Heterosexual Adults: Results from a Multi-State Probability-Based Sample. PLoS ONE, 8, e54691. http://dx.doi.org/10.1371/journal.pone.0054691

[34] Siemieniuk, R., Miller, P., Woodman, K., Ko, K., Krentz, H.B. and Gill, M.J. (2012) Prevalence, Clinical Associations, and Impact of Intimate Partner Violence among HIV-Infected Gay and Bisexual Men: A Population-Based Study. HIV Medicine, 14, 293-302. http://dx.doi.org/10.1111/hiv.12005

[35] Welles, S.L., Corbin, T.J., Rich, J.A., Reed, E. and Raj, A. (2011) Intimate Partner Violence among Men Having Sex with Men, Women, or Both: Early-Life Sexual and Physical Abuse as Antecedents. Journal of Community Health, 36, 477-485. http://dx.doi.org/10.1007/s10900-010-9331-9

[36] Preston, D.B., D’Augelli, A.R., Kassab, C.D. and Starks, M.T. (2007) The Relationship of Stigma to the Sexual Risk Behavior of Rural Men Who Have Sex with Men. AIDS Education and Prevention, 19, 218-230. http://dx.doi.org/10.1521/aeap.2007.19.3.218

[37] Rees, J. (2012) The Extra Challenges of HIV Stigma in a Rural Community. HIV Nursing, 12, 3-5.

[38] Delgado-Rodriguez, M. and Llorca, J. (2004) Bias. Journal of Epidemiology \& Community Health, 58, 635-641. http://dx.doi.org/10.1136/jech.2003.008466 